\title{
Assessment of the energy and separation efficiency of the decanter centrifuge with regulation capability of oil water ring in the industrial process line using a continuous method
}

\author{
Biagio Bianchi, Antonia Tamborrino, Francesco Santoro \\ Department of Agricultural and Environmental Science, University of Bari, Italy
}

\begin{abstract}
The third era in olive oil extraction sees a new generation of decanter that give the operator the possibility to chose time by time the type of working: two or three phase shifting from one solution to the other without stopping the machine and even intermediate solutions between two or three phase, making the most suitable adjustments, following olive variety, just as the machine works. A decanter centrifuge was employed during the experimental tests with variable differential speed between bowl and screw conveyor $(n)$ and with regulation capability of oil-pulp ring levels. Thus permit to shift from three to two phase, reducing water added and discharging the following byproducts: dehydrated husk similar to that of three-phase and recovers a wet pulp that is the between the liquid phase and the solid phase.

This paper aims to report the preliminary results of the energy and functional efficiency of the decanter when it works in the industrial scale plant and using a continuous method. The tests were carried out at two different flow rate values; for each flow rate the different variable differential speed between bowl and screw conveyor was varied at $15,50,17,50$ and 19,50. Quality olive, operating speed of the crusher machine and relative feed flow rate of the machine, the malaxing time and the degree of dilution of the paste, as well as the oil-pulp ring level were the same for all the trials. Irrespective of the flow rate and $n$ used, the machine tends to stabilize energy consumption in a very short time and values were quite similar to each other. The reductions in flow rate do not involve reductions of energy consumption indeed lead to the increase of absorption per unit mass of product worked. For
\end{abstract}

Correspondence: Antonia Tamborrino, DISAAT, University of Bari, via Amendola 165/A - 70126 Bari, Italy.

Tel.: +39.080.5443122 - Fax: +390805443122.

E-mail: antonia.tamborrino@uniba.it

Key words: olive oil extraction; decanter centrifuge; energy and separation efficiency.

Contributions: the authors contributed equally.

Conflict of interests: the authors declare no potential conflict of interest.

(C) Copyright B. Bianchia et al., 2013

Licensee PAGEPress, Italy

Journal of Agricultural Engineering 2013; XLIV(s2):e56

doi:10.4081/jae.2013.s2.e56

This article is distributed under the terms of the Creative Commons Attribution Noncommercial License (by-nc 3.0) which permits any noncommercial use, distribution, and reproduction in any medium, provided the original author(s) and source are credited. all thesis studied, no significant changes of the oil recovery efficiency were found, indeed changing the flow rate and the $\mathrm{n}$ a different distribution of the not extracted oil was found in the pulp and in the husk. To complete the knowledge, a set of tests changing also the oil-pulp ring levels, has been provided for the next olive oil season.

\section{Introduction}

Industrial production of olive oil is supported by centrifugal extraction since the 1970s. Until well into the 1970s, after crushing, stirring and heating it was standard practice to squeeze the olive using hydraulic presses and to separate the liquid obtained into oil and water phases in small disk separators or static sedimentation tanks - a very complex procedure with relatively low outputs. Initially 3-phase decanters were introduced. This 3-phase technology involved diluting the olive pulp with water, enabling the oil to be separated from the solid matter and water - an economical method, but one which, because of its requirement for huge volumes of fresh water, placed a significant burden on the environment. The quantities of wastewater also proved to be an ecological problem (Roig et al., 2006).The 3-phase decanters are able to separate oil from the husk (solide residues of olive) and waste water; due to the large amount of water added to the process a considerable reduction of natural antioxidant in the resulting olive oil is observed. The crucial advance came in the form of the 2-phase system. This was a method developed in the early 1990, which uses no added water for dilution and produces correspondingly less wastewater. What both processes have in common is that the olives are initially reduced to a pulp. With 3-phase technology, this olive pulp must be diluted with warm water so a layer forms between the oil and solids in the decanter. This is the only way to achieve the subsequent separation into oil phase, husk and wastewater. Depending on the type of olive, the required volume of water is 15 to 30 percent, in rare cases as much as 50 percent. The amount of loaded wastewater produced by this process is correspondingly high. In the 2-phase system, the preliminary treatment of the olives is essentially the same as in a 3-phase system. However, the fruits are milled smaller and malaxed for longer. The 2-phase decanters are able to separate the oil from the olive paste producing a pomace only, and for this reason are called '2-phase decanters'. They produce a very wet husk, with water content between 65 and $70 \%$ by weight. In addition to the ecological issues, the 2 -phase system is also impressive from an economic perspective. It ensures the best possible oil quality by retaining the highest possible polyphenol content. The taste is intense, because many flavours and ingredients are washed out to a much lesser extent due to the addition of less water. At the same time, these oils have an exceptionally long shelf life (Alburquerque et al., 2004). In 1997 an innovative type of decanter (VDP-decanter) was introduced with a more advanced system to regulate the processing conditions. This allows to obtain better results 
according to the variation of the ratio between liquid and solid phases, thus optimizing operational performances in relation to the rheological features of olive oil pastes. The decanter centrifuge were design with an innovative geometry, made by a longer cylindrical part of the bowl and shorter beach sections, and a special bowl with a variable dynamic pressure (VDP) cone system. This makes it possible to electronically adjust the speed of the screw according to the torque on the conveyor screw. Moreover, with the VDP the automatic control of differential speed depends on the twisting moment, thus obtaining drier discharged solids, with lower oil residue contents (Catalano et al., 2003). This decanters are able to work using a small amount of added water ( 0 to 20 percent of the weight of the olives) reducing the waste water discharged and producing a pomace with a water content between 55 and $60 \%$.

The latest development in this field is the new generation of decanter that give the operator the possibility to chose time by time the type of working: 2 or 3-phase shifting from one solution to the other without stopping the machine and even intermediate solutions between 2 or 3-phase, making the most suitable adjustments, following olive variety, just as the machine works. Thus permit to shift from 3 to 2-phase, reducing water added and discharging the following by-products: dehydrated husk similar to that of three-phase and recovers a wet pulp that is the between the liquid phase and the solid phase (Altieri 2010). Regarding the energy consumption in the olive oil extraction plants few studied have been done. In 1994 Morello studying continuous plants of the low work capacity (about $1500 \mathrm{~kg} / \mathrm{h}$ ) highlighter that the utilization of the installed electrical power varies between 20 and $40 \%$, with values minimum (20-25\%) for the extraction equipment: feed pumps, decanter, vibrating screens; the same equipment commits about $25 \%$ of the electricity used, with a power consumption of primary specific energy about 70-100 MJ/t of olives, equal to about $20 \%$ of the total energy. The optimization of the energy consumption of the decanter thus assumes considerable importance in the total energy balance and in production costs of the extra virgin olive oil.

This paper aims to report the preliminary results of the energetic and functional efficiency of the decanter when it works in the industrial scale plant and using a continuous method. The purpose has been to evaluate the performance of the decanter with appropriate adjustments of the functional parameters: different conveyor/bowl differential speed (Dn) and different mass flow rate of olive paste (Qp).

\section{Materials and methods}

\section{Industrial tests}

The experimental tests were carried out in an industrial olive oil mill located in Trani (BA), Italy. The extraction plant was equipped with a hammer crusher followed of a set of malaxer machine connected in series. The number of malaxer used was four; in this condition the paste fell, helped also to the movement of the reel, in the next malaxer and later in the next one until to feed the decanter. The paste was discharged by means at a "mono" type pump that feeds a centrifuge machine for oil recovery. The decanter centrifuge used was designed and built by the Barracane company (Modugno - BARI, ITALY) - MEGALA 650; the continuous extraction olive oil plant work up to $6500 \mathrm{~kg} / \mathrm{h}$ as a maximum work of throughput. This type of decanter is an twophase decanter that produce, as a by-products, a dehydrated husk similar to the one coming from a three-phase decanter and a wet pulp called "pâté" made up the only pulp of olives without any traces of kernel.

\section{Design features of the decanter centrifuge}

The decanter centrifuge with variable differential speed between bowl and screw conveyor $(\Delta \mathrm{n})$ and with regulation capability of oilwater ring level was used. The power-transmission technology between the conveyor and bowl developed in this decanter could be defined "electro-mechanical recovery":

- Maximum work of throughput: $6500 \mathrm{~kg} / \mathrm{h}$;

- Main electric power: $75 \mathrm{~kW}$;

- Supply voltage: $380 \mathrm{~V}$ three-phase;

- Rated power asynchronous bowl electric motor: $45 \mathrm{~kW}$;

- Rated current bowl electric motor: $80 \mathrm{~A}$;

- $\cos \phi$ bowl electric motor: 0.87;

- Rotational speed of the bowl electric motor: $1475 \mathrm{rev} / \mathrm{min}$;

- Rated power asynchronous screw conveyor electric motor: $30 \mathrm{~kW}$;

- Rated current screw conveyor electric motor: $54.4 \mathrm{~A}$;

- cos screw conveyor electric motor: 0.87;

- Rotational speed of the screw conveyor electric motor: $1470 \mathrm{r} / \mathrm{min}$.

In Figure 1 is sketched the electro-mechanical transmission that characterizes the external bowl and the coaxial inner screw conveyor motion. At the end of the cylindrical section of the bowl there are the exits of the olive oil and of the semifluid fraction made of pitted pulp and water. At about 1/3 of the screw conveyor hollow shaft total length there is the input section of the braked olive paste. The external bowl electric motor is powered by an inverter that is itself controlled by a knob in order to modify the rotation speed of the olive pasta; in the same way the supply of the screw conveyor electric motor is made whose rotation speed is controlled also by a planetary gearbox which fixes a 1:3 constant transmission ratio.

The bowl electric motor inverter is connected in series to the one of the screw conveyor electric motor which is itself connected to the public power supply network.

The olive paste, once has been introduced into the decanter, is obliged to rotate at the same angular speed of the bowl forcing the internal screw conveyor to rotate at the same angular speed which is however set to be lower; so the screw conveyor electric motor behaves as a generator so that the produced energy is used by the bowl electric motor with a fewer public supply network energy consumption.

The machine is also equipped with a system of pick-up diameters setting of both olive oil and olive paste. On the external bowl conical part surface, near its end, there are the husk exit holes.

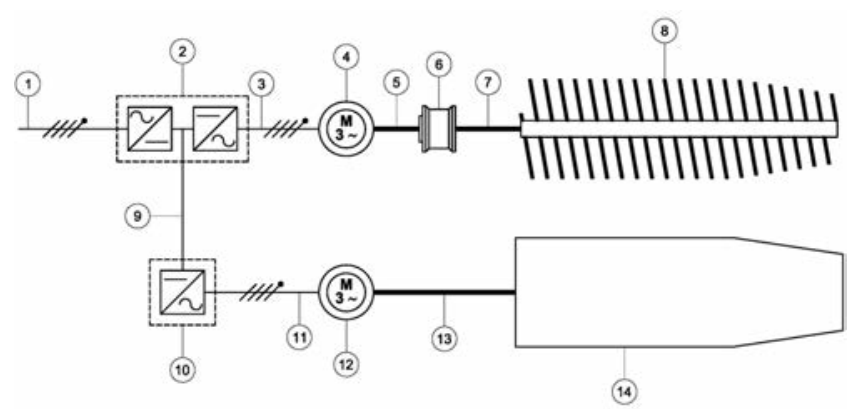

Figure 1. Decanter electro-mechanical transmission: 1 power supply, 2 screw conveyor energy recovery inverter, 3 screw conveyor electric motor power supply, 4 screw conveyor electric motor, 5 electric motor shaft, 6 planetary gearbox, 7 screw conveyor belt transmission, 8 screw conveyor, 9 inverter series connection, 10 bowl inverter, 11 bowl electric motor power supply, 12 bowl electric motor, 13 bowl belt transmission, 14 bowl. 


\section{Experimental procedure}

Olive fruits of constant quality (cv. Peranzana) were used for the trials. After the leaf-removal the olives were crushed and malaxed in continuous. The trials were divided in six tests and to ensure an average working time of about 60 minutes were used 10 minutes to stabilize the functioning of the decanter centrifuge and 50 minutes available for sampling. For each test paste was malaxed for 60 minutes at $28^{\circ} \mathrm{C}$.

During the continuous process of extraction were tested 2 different nominal values of paste mass flow rate, $4800 \mathrm{~kg} / \mathrm{h}$ and $4000 \mathrm{~kg} / \mathrm{h}$. For each value of paste mass flow rate the differential speed between the screw conveyor and bowl $(\Delta \mathrm{n})$ was varied at $15.50,17.50,19.50$. For all the tests no variation of the ring level was done as well as the water flow rate added to the process that was equal to $380 \mathrm{~kg} / \mathrm{h}$. This corresponds to about $8 \%$ of the first value of paste mass flow rate and about $10 \%$ of the second value.

\section{Industrial tests: power consumption}

In order to carry out the power consumption related industrial tests a measurement instrumentation chain has been arranged:

1 Digital built in frequency, current and voltage RS232 output of the

KEB COMBIVERT F6-K - inverter;

2 RS232 to USB converter;

3 Personal computer;

To achieve the desired differential speed Dn above specified for each test, the frequency of the input voltage of the two electrical motors of both screw conveyor and bowl, has been controlled; these values has been continuously verified during the tests.

The instrumentation chain was arranged to a data acquisition rate of 106 data per second (dps). The parameters monitored during the tests were:

- Bowl electric motor current consumption;

- Bowl electric motor power consumption;

- Screw conveyor electric motor current consumption/production;

- Screw conveyor electric motor power consumption/production.

The acquired data were processed using software specifically designed for this aim and the data have been treated with a statistical software.

\section{Industrials tests: mass balance}

The parameters used for the mass balance of the decanter centrifuge are: $Q_{p}$ : actual olive paste flow mass, $(\mathrm{kg} / \mathrm{h}) ; \mathrm{Q}_{0}$ : Olive oil flow mass $(\mathrm{kg} / \mathrm{h}) ; \mathrm{Q}_{\mathrm{w}}$ : Process water flow mass $(\mathrm{kg} / \mathrm{h}) ; \mathrm{Q}_{\mathrm{wp}}$ : Wet pulp flow mass $(\mathrm{kg} / \mathrm{h}) ; \mathrm{Q}_{\mathrm{h}}$ : Husk discharge flow mass $(\mathrm{kg} / \mathrm{h})$. In the mass balance the following $Q$ are known: $Q_{p}, Q_{0}, Q_{w}$ and $Q_{w p}$ whereas the $Q_{h}$ was obtained by application of the following equation: $Q_{h}=Q_{p}-Q_{0}-Q_{w p}$.

For each test a sample was taken of olive, of olive paste and two samples (one every 20 minutes) of wet pulp and husk. Moisture content of olive paste, husk and wet pulp were done. The analysis was based on weigh difference after sample drying, according to the official method. Fat content was assessed using a solvent extractor based on the Randall 148 extraction technique (VELP SCIENTIFICA). All analyses were carried out in triplicate. The separation efficiency was calculated from values obtained, as a percent ratio between oil extracted during process and oil contained in olives, as well as oil lost in wet pulp and husk.

\section{Statistical analysis}

Statistical analysis and plotted results were carried out using Statistica software (STATISTICA; Statsoft version 9.1).

\section{Results and discussions}

\section{Energy efficiency}

Based on experimental tests results, it's possible to note that irrespective of the flow rate and $\Delta \mathrm{n}$ used, the machine tends to stabilize energy consumption in a very short time (less than 10,0 s) and values are quite similar to each other. The reductions in flow rate do not involve reductions of energy consumption indeed lead to the increase of absorption per unit mass of product worked. The machinery energy consumption (Table 1) can be considered fairly constant with $\Delta \mathrm{n}$ variation. Irrespective of the studied working condition, even if the energy consumption are almost equal each other with current consumptions that varies from 50 to $60 \mathrm{~A}$, it's possible to detect a trend in electric power consumption rising when lowering $\Delta \mathrm{n}$ and vice versa: the higher $\Delta \mathrm{n}$ values carried out tests show lower electric power consumption for both the studied supply flows.

This result can be explained if it is considered that rising the bowlscrew conveyor differential speed involves a fewer time during which the olive paste stays in the machine which in turn involves a more fluid olive paste with a lower resistant torque on the screw conveyor.

This last eventuality also shows that the energy lost due the resistant torque on the screw conveyor is much more greater than the one lost in the planetary gearbox even if it should increase with higher $\Delta \mathrm{n}$. However the machinery energy recovery system allows the bowl electrical motor to really use fewer electric energy from the public electric energy network then theoretically needed; in fact during regime phase, the screw conveyor is dragged along by the bowl, so its electrical motor acts as a generator and the produced energy is used by the bowl electrical motor.

This behavior is shown by negative current measurement at the screw conveyor electrical motor during regime phase (Table 1). With an independent transmission system, the bowl electrical motor used energy would have been greater.

Collected energy data analysis shows a not significant variation related to a paste flow supply reduction thus it should be better to let

Table 1. Experimental test measured energetic parameters mean values.

\begin{tabular}{|c|c|c|c|c|c|c|c|c|c|c|}
\hline Test & $\begin{array}{l}\mathrm{BC}_{\mathrm{s}} \\
\text { (A) }\end{array}$ & $\varepsilon$ & $\begin{array}{c}\mathrm{SCC}_{\mathrm{S}} \\
\text { (A) }\end{array}$ & $\varepsilon$ & $\begin{array}{l}\mathrm{BC}_{\mathrm{R}} \\
\text { (A) }\end{array}$ & $\varepsilon$ & $\begin{array}{c}S C C_{R} \\
\text { (A) }\end{array}$ & $\varepsilon$ & $\begin{array}{l}\mathrm{TC}_{\mathrm{R}} \\
\text { (A) }\end{array}$ & $\varepsilon$ \\
\hline A & 77 & 3,04 & 25 & 0,95 & 68 & 3,24 & -16 & 3,12 & 52 & 3,49 \\
\hline A+ & 76 & 1,98 & 24 & 1,31 & 67 & 1,74 & -17 & 2,34 & 50 & 1,83 \\
\hline A- & 78 & 2,87 & 27 & 0,92 & 67 & 3,76 & -12 & 2,97 & 55 & 1,85 \\
\hline B & 74 & 3,65 & 26 & 1,65 & 68 & 2,48 & -10 & 3,12 & 58 & 1,74 \\
\hline $\mathrm{B}+$ & 76 & 3,88 & 24 & 1,42 & 66 & 3,01 & -10 & 3,47 & 56 & 2,23 \\
\hline B- & 77 & 2,62 & 26 & 0,57 & 69 & 2,12 & -9 & 3,21 & 60 & 2,43 \\
\hline
\end{tabular}

$\mathrm{BC}_{\mathrm{s}}$ : Bowl current consumption at start-up phase; $\mathrm{SCC}_{\mathrm{S}}$ : Screw conveyor current consumption at start-up phase; $\mathrm{BC}_{\mathrm{R}}$ : Bowl current consumption at regime phase; $\mathrm{SCC}_{\mathrm{R}}$ : Screw conveyor current consumption at regime phase; $\mathrm{TC}_{\mathrm{R}}$ : Total current consumption at regime phase. 
Table 2. Oil balance for all the trials as a function of the processing conditions.

\begin{tabular}{|c|c|c|c|c|c|c|c|c|c|}
\hline \multirow[t]{3}{*}{ Test } & \multirow[t]{3}{*}{$\begin{array}{l}\text { Qp } \\
(\mathrm{kg} / \mathrm{h})\end{array}$} & \multirow[t]{3}{*}{$\begin{array}{l}\text { Processing water } \\
\text { (\%) }\end{array}$} & \multirow[t]{3}{*}{$\Delta \mathrm{n}$} & \multirow{2}{*}{\multicolumn{2}{|c|}{$\begin{array}{l}\text { Extraction efficiency } \\
(\%)\end{array}$}} & \multicolumn{4}{|c|}{$\begin{array}{l}\text { Residual oil content } \\
(\mathrm{kg} / 100 \mathrm{~kg})\end{array}$} \\
\hline & & & & & & \multicolumn{2}{|c|}{ Husk } & \multicolumn{2}{|c|}{ Wet pulp } \\
\hline & & & & $\mathrm{m}$ & DS & $\mathrm{m}$ & DS & m & DS \\
\hline A & 4809,6 & 8 & 17,50 & 90,2 & \pm 0.11 & 3,68 & \pm 0.01 & 6,08 & \pm 0.02 \\
\hline A - & 4809,6 & 8 & 15,50 & 88,7 & \pm 0.12 & 8,94 & \pm 0.02 & 2,35 & \pm 0.03 \\
\hline$A+$ & 4809,6 & 8 & 19,50 & 89,3 & \pm 0.19 & 7,62 & \pm 0.02 & 3,11 & \pm 0.01 \\
\hline B & 4075,2 & 10 & 17,50 & 89,3 & \pm 0.20 & 7,88 & \pm 0.03 & 2,79 & \pm 0.03 \\
\hline B - & 4075,2 & 10 & 15,50 & 90,4 & \pm 0.12 & 7,27 & \pm 0.01 & 2,31 & \pm 0.02 \\
\hline$B+$ & 4075,2 & 10 & 19,50 & 90,3 & \pm 0.19 & 6,99 & \pm 0.01 & 2,71 & \pm 0.02 \\
\hline
\end{tabular}

the machine work at its maximum working capacity because the power consumption per mass unit should be the lowest. This result could be useful in the olive mill management; as a matter of fact the paste flow supply rate is the main operating parameter modified in order to solve abnormal working conditions. Conversely, on this specific machinery, since a lot of working parameters can be modified without outages, the energy consumption could be optimized modifying other working parameters such as $\Delta \mathrm{n}$ or the pick-up diameters instead of paste flow supply.

\section{Separation efficiency}

The extraction efficiency varies from 80 to $90 \%$ of the oil content of the olives, because the oil in the olive paste is only partially free to escape and part of it remain in unbroken olive cells or is trapped in the tissues of cytoplasm or is emulsified in the aqueous phase. The residual oil in the olive by-products is a critical point in the olive oil extraction process. Furthermore, the olive husk is sold to other factories, where the olive oil residual is extract by solvent extraction to obtain the "olive pomace oil". But, before this, the by-products could be sent to another decanter associated to the firsts extractions equipment line, in the same facilities, where usually is added water and started a process to recovery the amount of oil residual, obtaining the oil so called "oil from ripasso".

The results of trials, are reported in Table 2, as a function of the processing conditions, i.e. feeding, and differential velocity of the conveyor to the bowl. For all conditions studied, there have been no significant changes in the performance of the machine in terms of oil extracted. In particular, the total amount of oil that has been not extracted, thus present in the husk and in the wet pulp, is never greater than $2.8 \%$ on the total mass of the obtained residues (13\% on the oil present in olives). Besides, in all samples of wet pulp, no fragment of stones has been detected; this open an interesting scenario in the reuse of this byproduct for composting or animal feeding.

A complete analysis of the effects of the various process parameters on the extraction efficiency of this type of decanter was performed: the oil content in the wet pulp and in the husk has been determined and in the Table 2 the main differences between the different operating conditions are shown. The composition of the by-products, in terms of oil residual, is influenced by the operating conditions used: flow mass rate and Dn. Different flow mass rate and different Dn determines a different amount of the residual oil in the two by-products discharged: wet pulp and husk. The condition of the Test A determines an amount of residual oil in the wet pulp greater than that present in the husk. This condition makes much convenient to extract the residual oil only from
Table 3. Flow mass balance for all tested conditions.

\begin{tabular}{lccccc} 
Test & $\begin{array}{c}\text { Qp } \\
(\mathrm{kg} / \mathrm{h})\end{array}$ & $\begin{array}{c}\text { Qw } \\
(\mathrm{kg} / \mathrm{h})\end{array}$ & $\begin{array}{c}\text { Qo } \\
(\mathrm{kg} / \mathrm{h})\end{array}$ & $\begin{array}{c}\text { Owp } \\
(\mathrm{kg} / \mathrm{h})\end{array}$ & $\begin{array}{c}\text { Qh } \\
(\mathrm{kg} / \mathrm{h})\end{array}$ \\
A & 4809,6 & 379,5 & 1005 & 1551 & 2633,1 \\
A - & 4809,6 & 379,5 & 888 & 1332 & 2969,1 \\
\hline A & 4809,6 & 379,5 & 966 & 1212 & 3011,1 \\
B & 4075,2 & 379,5 & 768 & 990 & 2696,7 \\
\hline B - & 4075,2 & 379,5 & 828 & 999 & 2627,7 \\
B + & 4075,2 & 379,5 & 788 & 987 & 2679,7 \\
\hline
\end{tabular}

the wet pulp using a intended decanter ensuring, besides, the highest amount of residual oil in the lower quantity of by-product treaty allows to reduce both investment costs, relative to the machines and the overall dimensions allocated to this operation, both the costs of management. Reducing the nominal work throughput at $4000 \mathrm{~kg} / \mathrm{h}$ and setting 19,50 as Dn (test B), the greater amount of residual oil was founded in the husk with the same extraction efficiency for both the tests (test A and test B). The evaluation of mass balances and the comparison of results in different operating conditions can suggest optimal operating conditions of the extraction process.

\section{Conclusions}

The peculiarity of the present study is the use of an industrial olive mill. So on the one hand has been difficult to identify the right processruling parameters, and sometimes even understand them, but on the other hand the obtained results are immediately usable by the olive mills managers because these results are obtained on a real-scale model towards an experimental-scientific approach.

The obtained experimental tests results shows high performances and significant flexibility potential of the studied machine both by an energy consumption point of view and by a functional one if referring to oil extraction efficiency and wastes management.

Some of the obtained results are the basis of the present study hereinafter that should be held in the next olive production season. During the following research step, the decanter will be optimised in order to achieve the higher yield, the lowest energy consumption and an easy management of residual oil both in the wet pulp and in the husk, with the final result to produce easy to use iso-yielding charts. 


\section{References}

Alburquerque, J.A., Gonza lvez, J., Garcı a, D., Cegarra, J. Agrochemical characterisation of "alperujo", a solid by-product of the two phase centrifugation method for olive oil extraction. Bioresource Technology. 2004; 92(2): 195-200.

Altieri, G., Comparative trials and an empirical model to asses throughput indices in olive oil extraction by decanter centrifuge. Journal of food engineering. 2010; 97:46-56.

Catalano, P., Pipitone, F., Calafatello, A., Leone, A. Productive Efficiency of Decanters with Short and Variable Dynamic Pressure Cones. Biosystems Engineering. 2003; 86(4):459-464.

Morello G., Peri G., Planeta A. Aspetti energetici dell'estrazione dell'olio di oliva in impianti a ciclo continuo. Proceedings book "Aspetti Energetici del Sistema Agro-Industriale e Loro Influenza sul Territorio". 1994; 1:199-215.

Roig, A., Cayuela, M.L., Sa nchez-Monedero, M.A. An overview on olive mill wastes and their valorisation methods. Waste Management. $2006 ; 26: 960-969$. 